\title{
Vaudois et Confédérés au service de France,
} 1789-1798

Michel Biard

\section{Q OpenEdition \\ 12 Journals}

Édition électronique

URL : https://journals.openedition.org/ahrf/952

DOI : 10.4000/ahrf.952

ISSN : 1952-403X

\section{Éditeur :}

Armand Colin, Société des études robespierristes

\section{Édition imprimée}

Date de publication : 1 mars 2000

Pagination : 165-166

ISSN : 0003-4436

\section{Référence électronique}

Michel Biard, «Vaudois et Confédérés au service de France, 1789-1798 », Annales historiques de la Révolution française [En ligne], 319 | janvier-mars 2000, mis en ligne le 10 avril 2006, consulté le 24 avril 2022. URL : http://journals.openedition.org/ahrf/952 ; DOI : https://doi.org/10.4000/ahrf.952

Ce document a été généré automatiquement le 24 avril 2022.

Tous droits réservés 


\title{
Vaudois et Confédérés au service de France, 1789-1798
}

\author{
Michel Biard
}

\section{RÉFÉRENCE}

Alain-Jacques TORNARE, Vaudois et Confédérés au service de France, 1789-1798, Yens s./ Morges, éditions Cabédita, 1998, 271 p.

1 Issu d'une thèse de doctorat (complétée par d'autres recherches), l'ouvrage d'Alain-Jacques Tornare est consacré, non seulement à la présence militaire suisse en France pendant la Révolution, mais aussi au rôle particulier des Vaudois et autres francophones au sein des régiments suisses. De toute évidence, l'auteur inscrit son travail dans l'historiographie de la Révolution française tout autant que dans le cadre des querelles intestines qui agitent la confédération. L'ouvrage alterne parcours thématique et parcours événementiel, donnant une entière liberté au lecteur qui peut ainsi soit aller du 14 juillet au 10 août en passant par l'«année malheureuse» pour les Suisses (1790), soit privilégier une réflexion centrée sur le rôle des Suisses dans la séquence révolutionnaire.

2 Après avoir rappelé les origines des relations franco-helvétiques, Alain-Jacques Tornare montre comment à la veille de 1789 l'état des troupes suisses en France est loin d'être parfait. Les contestations du service étranger, précocement apparues (avec notamment Zwingli), se font de plus en plus vives en Suisse cependant qu'en France l'utilité de ces troupes semble de moins en moins évidente. Leur coût, leurs privilèges, leur répugnance au service sur mer, leur non-participation au conflit d'Amérique, tout concourt au déclin des régiments suisses qui, pour certains, se retrouvent occupés au dessèchement de marais ou à l'entretien du réseau routier. Même si les effectifs avoisinent les 14000 hommes, «le service de France est mort à petit feu et pas seulement sous celui des révolutionnaires». En opposition avec la légende historiographique, aussi bien suisse que contre-révolutionnaire, qui ne veut retenir que 
la seule image de soldats étrangers fidèles jusqu'au bout à la monarchie et versant leur sang alors que les défenseurs du roi se raréfient, Alain-Jacques Tornare note combien sont nombreux les signes de découragement qui touchent la «piétaille» comme le commandement. Grâce aux nombreux et passionnants témoignages retrouvés par l'auteur, l'état d'esprit des soldats suisses paraît sous un jour nouveau. En effet, dès l'été 1789 , les actes d'indiscipline se multiplient, notamment dans le régiment des gardes suisses à Paris où des soldats exigent leur congé, parfois les armes à la main. Le malaise profond qui existait avant la rupture de 1789 se combine alors avec la conjoncture politique révolutionnaire pour amener une baisse sensible des effectifs. Ainsi le régiment des gardes suisses qui comptait environ 2400 hommes en octobre 1788 n'en compte plus que 1940 à la fin d'août 1789 (avant de revenir à environ 2100 en décembre). Là où certaines compagnies perdent la moitié de leurs effectifs, d'autres ne sont presque pas touchées, sans que l'on puisse conclure, selon l'auteur, à un rôle décisif joué par les francophones (il reste néanmoins évident que Genevois et Vaudois ont forcément eu davantage de facilités pour entrer en contact avec les révolutionnaires parisiens). Quoique nettement affaiblies, les troupes suisses ne connaissent donc pas une contagion généralisée telle qu'elle a pu s'opérer par exemple pour les gardes françaises.

Pour autant, à leur corps défendant, les Suisses jouent un rôle de catalyseur pour le mouvement révolutionnaire, tout d'abord par le cas particulier du régiment de Châteauvieux, puis par leur image de troupes «naturellement» suspectes. Alain-Jacques Tornare évoque l'attitude des Suisses de Châteauvieux en juillet 1789 et utilise le terme de «mythe» à propos du refus de ces soldats de porter les armes contre le peuple parisien. Pourtant, s'il est vrai que l'épisode a été magnifié en 1790 , donc a posteriori (mais est-ce vraiment étonnant?), aucune preuve susceptible de nier l'épisode n'est apportée par l'auteur. De même peut-il paraître exagéré de soutenir que sans la présence des Suisses à Paris, notamment dans la garnison de la Bastille, les Parisiens se seraient sans doute moins mobilisés. À propos des événements de Nancy, l'auteur soutient par contre de façon convaincante qu'il s'agissait surtout de faire un exemple, ce qui était moins difficile avec un régiment suisse qu'avec un régiment français, d'autant que les officiers de Châteauvieux étaient prêts à assumer sans états d'âme la répression. Restait à monter la provocation, avec Malseigne et Bouillé comme artisans essentiels de l'opération qui aboutit aux violents combats de Nancy. Ici encore il est cependant délicat de suivre sans réserves l'auteur lorsqu'il renvoie dos à dos les contre-révolutionnaires qui ont voulu l'épreuve de force et les Jacobins qui en ont tiré profit politique à plus long terme. Certes la récupération est patente, avec comme apogée la fête de Châteauvieux en 1792, mais au regard de la centaine de morts (dont vingt-neuf mutins), des cent vingt-huit Suisses condamnés dont vingt-deux sont pendus et un autre roué vif tandis que quarante et un sont envoyés aux «galères» à Brest, est-il utile de parler de «battage publicitaire sans précédent» opéré par «ces ancêtres des professionnels du spectacle»? Par ailleurs, Alain-Jacques Tornare met bien en évidence que les soldats suisses de 1792 sont incontestablement les jouets d'un mouvement révolutionnaire qui les utilise, soit pour les glorifier (les "galériens» délivrés et fêtés), soit pour les vilipender car leur image est liée à celle d'un régime en perte de vitesse. La dégradation des rapports entre les Suisses du régiment d'Ernst et la population marseillaise, le rôle des gardes suisses à Paris, tout atteste que dans l'imaginaire populaire les habits rouges sont devenus d'inconditionnels soutiens de la «tyrannie», ce qui n'est pas pour rien dans la violence des combats et la passion 
vengeresse du 10 août 1792. Les Suisses, qui avaient été perçus autrefois comme des mercenaires (terme contesté par Alain-Jacques Tornare) recrutés pour défendre les frontières et économiser le sang français, sont devenus en 1792 non seulement un corps étranger à la nation, un corps privilégié dans un univers où tout privilège est honni, mais aussi et surtout une force au service d'un ordre contesté. L'élimination des gardes suisses le 10 août et le licenciement des régiments helvétiques (pour l'essentiel en septembre et octobre 1792) marquent en apparence la fin de l'épisode, même si certains soldats s'engagent aussitôt au service de la République et si d'autres le font dans le cadre de la capitulation conclue en 1798.

Bien documenté, agrémenté d'une riche iconographie, doté d'une utile chronologie, l'ouvrage d'Alain-Jacques Tornare devrait, en dépit des quelques réserves émises, s'imposer comme une référence majeure sur la question et anéantir de façon définitive (du moins peut-on l'espérer) les trop nombreuses idées reçues qui, hélas, encombrent encore beaucoup d'ouvrages destinés à un large public. 